\title{
Letter
}

\section{A mild catalytic detoxification method for PCDDs and PCDFs}

\author{
Pietro Tundo ${ }^{\mathrm{a}, *}$, Alvise Perosa ${ }^{\mathrm{a}}$, Maurizio Selva ${ }^{\mathrm{a}}$, Sergei S. Zinovyev ${ }^{\mathrm{b}, 1}$ \\ a Dipartimento di Scienze Ambientali Università Ca' Foscari, Dorsoduro 2137, 30123 Venezia, Italy \\ b Consorzio Interuniversitario “la Chimica per l'Ambiente" (INCA), Dorsoduro 2137, 30123 Venezia, Italy
}

Received 3 December 2000; received in revised form 4 March 2001; accepted 4 March 2001

\begin{abstract}
The hydrodechlorination of environmental samples of toxic polychlorinated dibenzo- $p$-dioxins (PCDDs) and polychlorinated dibenzofurans (PCDFs), commonly "dioxins", was accomplished catalytically under mild conditions: $50^{\circ} \mathrm{C}$ and 1 atm of hydrogen. This catalytic detoxification methodology takes place in a multiphase reaction system (isooctane-water), with a supported metal catalyst (Pt or Pd) modified by a phase-transfer (PT) agent, Aliquat 336.

Environmental samples of PCDDs and PCDFs were extracted from the fly ashes of a municipal solid waste incinerator (MSWI), and had a relatively high toxicity equivalent concentration (572 and $735 \mathrm{pgTEQ} / \mathrm{ml}$, respectively).

The samples were successfully hydrodechlorinated using the described detoxification methodology, and yielded mixtures where the concentration of contaminants determined by GC-HRMS, was lower than the experimentally detectable limit. The procedure has the potential to become a practical method for the detoxification of PCDDs and PCDFs. (C) 2001 Elsevier Science B.V. All rights reserved.
\end{abstract}

Keywords: Polychlorinated dibenzo-p-dioxins; Polychlorinated dibenzofurans; Hydrodehalogenation; Catalytic detoxification

\section{Introduction}

The chemical degradation of persistent chlorinated aromatic pollutants such as polychlorinated dibenzo-p-dioxins (PCDDs) and polychlorinated dibenzofurans (PCDFs) has been approached by a number of methods. Our experience dates back to 1985 when 2,3,7,8-TCDD was reacted with an inorganic peroxide $\left(\mathrm{Na}_{2} \mathrm{O}_{2}\right)$ in the presence of a weak base, such as $\mathrm{K}_{2} \mathrm{CO}_{3}$, and yielded the completely dechlorinated

\footnotetext{
* Corresponding author. Fax: +39-041-2578620.

E-mail address: tundop@unive.it (P. Tundo).

${ }^{1}$ On leave from the N.D. Zelinsky Institute of Organic Chemistry of Russian Academy of Sciences, Leninsky pr. 47, Moscow 117913, Russia.
}

product [1]. A number of methods are reported for the catalytic reductive hydrodechlorination of chloroaromatics, for example polychlorobiphenyls were converted to biphenyl by Ni supported on silica, [2,3] by Pd supported on carbon in a continuous process [4], and by $\mathrm{Ni}-\mathrm{Mo} / \gamma-\mathrm{Al}_{2} \mathrm{O}_{3}$ [5]. Chlorobenzenes were reduced to benzene on alumina-supported $\mathrm{Pd}, \mathrm{Rh}$, or Ni [6-8]. All the preceding methods require however relatively high temperatures or pressures. Ukisu and co-workers have widely investigated the catalytic dechlorination of polychloroaromatics in the presence of carbon-supported $\mathrm{Pd}$ and $\mathrm{Rh}$ catalysts under mild conditions [9-12]. Other degradation procedures for chloroaromatics, such as oxidative $[13,14]$, radiolytic [15], or photochemical methods [16,17] have been described as well. 
An alternative methodology is the catalytic multiphase system for the hydrodechlorination of aromatics. This system consists of a hydrocarbon solvent and an aqueous phase, of a supported metal catalyst (Pt or $\mathrm{Pd}$ ) and of a phase-transfer (PT) agent as a promoter, and it allows the rapid and efficient hydrodehalogenation of various polyhalogenated aromatics with hydrogen [18-22]. This procedure affords quantitative yields of reduction products under mild conditions: hydrogen at atmospheric pressure and $50^{\circ} \mathrm{C}$. Under these conditions, a variety of aromatic halides, including hindered ones, undergo facile and progressive displacement of the halide atoms, and are eventually transformed into the desired hydrocarbons in substantially quantitative yields. This reduction reaction can be highly regio- and chemoselective, presumably because it takes place within the third liquid phase made by the PT agent which coats the supported metal catalyst [23-25]. This catalytic environment drives the significant modifications observed for the kinetics and selectivity of the reaction: the selective removal of halogen from aromatics and the selective reduction of other functional groups, these aspects of the reaction, along with some mechanistic considerations, have however been addressed elsewhere [25]. The present system is especially effective for dehalogenation, as demonstrated by the fact that in the absence of the PT agent, halogen removal is suppressed. It was in fact applied for the hydrodehalogenation of polyhaloaromatics [18-20], $p$-chloroacetophenone [25], $p$-chloropropiophenone [22-24] using various supported metal catalysts [18-20], PT agents [18-20,24], and hydrogen sources [26]. It is noteworthy that hydrodechlorination of PCBs afforded the fully dechlorinated product in $99 \%$ yield over the $\mathrm{Pd} / \mathrm{C}$ catalyst after $3 \mathrm{~h}$ at $50^{\circ} \mathrm{C}$ and $1 \mathrm{~atm} \mathrm{H}_{2}$ [18-20]. The same multiphase hydrodehalogenation reaction was used for the reduction of different functional groups on aromatic rings as well, e.g. acetophenone [25]. Something similar (except for the PT agent and the mild temperatures employed) to the reported $\mathrm{H}_{2}$ reduction of acetophenone over a $\mathrm{AlPO}_{4}-\mathrm{SiO}_{2}$-supported $\mathrm{Pd}$ catalyst [27,28].

This work describes the first application of this multiphase system to the degradation of the toxic congeners of PCDDs and PCDFs, collected from a municipal solid waste incinerator (MSWI). It is therefore a preliminary example of a practical degradation method applied to a real-world case. This could conceivably serve in the future for the on-site detoxification of concentrated samples of contaminants, such as the ones contained in the fly ashes of incineration processes or in filters for the abatement of toxic materials.

\section{Experimental}

The hydrodechlorination reactions were run in a $25 \mathrm{ml}$ three-necked water-jacketed reactor thermostated at $50^{\circ} \mathrm{C}$, loaded with $10 \mathrm{ml}$ of an isooctane solution of the substrate, Aliquat $336(0.26 \mathrm{mmol})$, $\mathrm{Pt} / \mathrm{C}$ or $\mathrm{Pd} / \mathrm{C}$ catalyst $(0.021 \mathrm{mmol}, 4.25$ and $9.72 \mathrm{wt} . \%$, respectively, on activated carbon particle size $325 \mathrm{mesh}$, surface area $900-1000 \mathrm{~m}^{2} / \mathrm{g}$ was used as purchased from Aldrich, catalog numbers 20,593-1 and 20,569-9, respectively), and $5.7 \mathrm{ml}$ of $1 \%$ aqueous $\mathrm{KOH}$ solution. Hydrogen was bubbled in the reaction mixture, stirred at approximately $1000 \mathrm{rpm}$ with an approximate flow rate of $5 \mathrm{ml} / \mathrm{min}$.

For the model substrate, 2,4,8-trichlorodibenzofuran (commercial reagent from Aldrich), the reaction was run with $10 \mathrm{ml}$ of $0.07 \mathrm{M}$ substrate in isooctane. The reaction was followed by $\mathrm{GC}$ and the products were analyzed by GC-MS. Both 5\% Pt and 10\% Pd carbon-supported catalysts were used. The results are reported in Fig. 1.

The degradation reaction was performed on two different samples (labeled A and B) of PCDDs/PCDFs, collected from a MSWI (fly ash extract) using $\mathrm{Pd} / \mathrm{C}$ as the catalyst, the initial concentrations were 735 and $572 \mathrm{pgTEQ} / \mathrm{ml}$ (toxicity equivalents), respectively. Sample A was available as a $n$-hexane solution, while sample B as a toluene solution, and were used as such ( $2 \mathrm{ml}$ were diluted with $8 \mathrm{ml}$ of isooctane). The concept of TEF (toxicity equivalent factor) has been developed to facilitate risk assessment [29]. TEF values for individual congeners in combination with their chemical concentration are used to calculate the total toxicity equivalents concentration (TEQs) contributed by all dioxin-like congeners. The TEF values refer to $2,3,7,8$-TCDD, the most toxic congener whose TEF is set to one. The equation for TEQ, which assumes dose additivity, is TEQ = $\sum\left(\mathrm{PCDD}_{i} \times \mathrm{TEF}_{i}\right)+\sum\left(\mathrm{PCDF}_{i} \times \mathrm{TEF}_{i}\right)$, and allows to relate the raw analytical data with the toxicity 


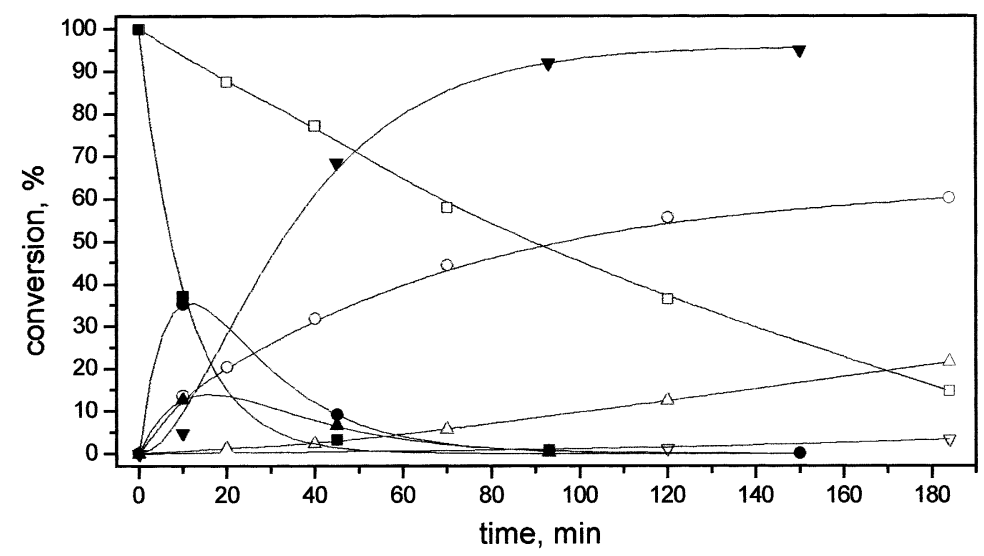

Fig. 1. Hydrodehalogenation of 2,4,8-trichlorodibenzofuran over $\mathrm{Pd} / \mathrm{C}$ (solid symbols) and $\mathrm{Pt} / \mathrm{C}$ (open symbols) in multiphase conditions: $(\boldsymbol{\square}, \square)$ 2,4,8-trichlorodibenzofuran $(2,4,8-\mathrm{TCDF}) ;(\boldsymbol{O}, \bigcirc)$ dichloro isomers $(\mathrm{DCDF}) ;(\boldsymbol{\Lambda}, \triangle)$ monochloro isomers $(\mathrm{CDF}) ;(\boldsymbol{\nabla}, \nabla)$ dibenzofuran (DF).

of the compounds. It gives a further measure of the practical applicability of this degradation method.

Extraction and high-resolution analyses of PCDDs/ PCDFs were performed according to the US-EPA method 1613 [30]. The sensitivity of the method was enhanced for the liquid samples by using a concentration of internal standards $\left({ }^{13} \mathrm{C}_{12}\right.$-labeled 2,3,7,8-PCDD/PCDF-substituted isomers) to deliver

Table 1

Hydrodechlorination of toxic PCDD/PCDF congeners under multiphase conditions over Pd/C: sample $\mathrm{A}^{\mathrm{a}}$

\begin{tabular}{|c|c|c|c|c|c|c|c|}
\hline \multirow[t]{2}{*}{$\mathrm{PCDD} / \mathrm{PCDF}$} & \multirow[t]{2}{*}{ TEF [29] } & \multicolumn{6}{|c|}{ Concentration $(\mathrm{pg} / \mathrm{ml})$} \\
\hline & & $0^{\prime}$ & $2^{\prime}$ & $5^{\prime}$ & $20^{\prime}$ & $40^{\prime}$ & $120^{\prime}$ \\
\hline 2,3,7,8-TCDD & 1 & 33 & $<1$ & $<1$ & $<1$ & $<1$ & $<1$ \\
\hline 1,2,3,7,8-PCDD & 1 & 104 & $<1$ & $<1$ & $<1$ & $<1$ & $<1$ \\
\hline 1,2,3,4,7,8-HCDD & 0.1 & 155 & 10 & $<2$ & $<2$ & $<2$ & $<2$ \\
\hline 1,2,3,6,7,8-HCDD & 0.1 & 673 & 34 & 13 & $<2$ & $<2$ & $<2$ \\
\hline $1,2,3,7,8,9-\mathrm{HCDD}$ & 0.1 & 502 & 15 & 9 & $<2$ & $<2$ & $<2$ \\
\hline $1,2,3,4,6,7,8-\mathrm{HpCDD}$ & 0.01 & 5186 & 219 & 61 & 32 & 10 & $<3$ \\
\hline $1,2,3,4,6,7,8,9-\mathrm{OCDD}$ & 0.0001 & 10610 & 407 & 90 & 51 & 15 & $<5$ \\
\hline TEQ (pgTEQ/ml) & & 323 & 10.1 & 5.0 & 2.7 & 2.4 & $<2.3$ \\
\hline 2,3,7,8-TCDF & 0.1 & 249 & $<1$ & $<1$ & $<1$ & $<1$ & $<1$ \\
\hline $1,2,3,7,8-\mathrm{PCDF}$ & 0.05 & 123 & 5 & $<1$ & $<1$ & $<1$ & $<1$ \\
\hline $2,3,4,7,8-\mathrm{PCDF}$ & 0.5 & 288 & 11 & $<1$ & $<1$ & $<1$ & $<1$ \\
\hline $1,2,3,4,7,8-\mathrm{HCDF}$ & 0.1 & 763 & 41 & 10 & 6 & $<2$ & $<2$ \\
\hline $1,2,3,6,7,8-\mathrm{HCDF}$ & 0.1 & 477 & 25 & 7 & $<2$ & $<2$ & $<2$ \\
\hline 2,3,4,6,7,8-HCDF & 0.1 & 792 & 38 & 8 & 6 & $<2$ & $<2$ \\
\hline $1,2,3,7,8,9-\mathrm{HCDF}$ & 0.1 & 48 & 16 & $<2$ & $<2$ & $<2$ & $<2$ \\
\hline $1,2,3,4,6,7,8-\mathrm{HpCDF}$ & 0.01 & 2414 & 163 & 27 & 14 & $<3$ & $<3$ \\
\hline $1,2,3,4,7,8,9-\mathrm{HpCDF}$ & 0.01 & 456 & 15 & $<3$ & $<3$ & $<3$ & $<3$ \\
\hline $1,2,3,4,6,7,8,9-\mathrm{OCDF}$ & 0.0001 & 2249 & 83 & 18 & 12 & $<5$ & $<5$ \\
\hline TEQ (pgTEQ/ml) & & 412 & 19.6 & 3.5 & 2.2 & $<1.1$ & $<1.1$ \\
\hline Total TEQ (pgTEQ/ml) & & 735 & 29.7 & 8.5 & 4.9 & 3.5 & $<3.4$ \\
\hline
\end{tabular}

a Symbol " $<$ " indicates that the concentration is under the detectability limit; in this case for the purpose of calculating TEQ, the concentration is always assumed $=1 \mathrm{pg} / \mathrm{ml}$. 
Table 2

Hydrodechlorination of toxic PCDD/PCDF congeners under multiphase conditions over Pd/C: sample $\mathrm{B}^{\mathrm{a}}$

\begin{tabular}{|c|c|c|c|c|c|}
\hline \multirow[t]{2}{*}{$\mathrm{PCDD} / \mathrm{PCDF}$} & \multirow[t]{2}{*}{ TEF [29] } & \multicolumn{4}{|c|}{ Concentration (pg/ml) } \\
\hline & & $0^{\prime}$ & $20^{\prime}$ & $60^{\prime}$ & $185^{\prime}$ \\
\hline 2,3,7,8-TCDD & 1 & 10 & 12 & 3 & 1 \\
\hline 1,2,3,7,8-PCDD & 1 & 56 & 11 & 3 & $<1$ \\
\hline $1,2,3,4,7,8-\mathrm{HCDD}$ & 0.1 & 105 & 2 & $<2$ & $<2$ \\
\hline 1,2,3,6,7,8-HCDD & 0.1 & 638 & 8 & 4 & $<2$ \\
\hline 1,2,3,7,8,9-HCDD & 0.1 & 351 & 13 & 6 & $<2$ \\
\hline 1,2,3,4,6,7,8-HpCDD & 0.01 & 3181 & 10 & 9 & $<3$ \\
\hline $1,2,3,4,6,7,8,9-\mathrm{OCDD}$ & 0.0001 & 4193 & 13 & 15 & $<5$ \\
\hline TEQ (pgTEQ/ml) & & 208 & 25.4 & 7.2 & $<2.3$ \\
\hline $2,3,7,8-\mathrm{TCDF}$ & 0.1 & 69 & 1 & 1 & $<1$ \\
\hline 1,2,3,7,8-PCDF & 0.05 & 89 & $<1$ & 1 & $<1$ \\
\hline 2,3,4,7,8-PCDF & 0.5 & 263 & 2 & 2 & $<1$ \\
\hline $1,2,3,4,7,8-\mathrm{HCDF}$ & 0.1 & 746 & 3 & 3 & $<2$ \\
\hline $1,2,3,6,7,8-\mathrm{HCDF}$ & 0.1 & 421 & $<2$ & 2 & $<2$ \\
\hline $2,3,4,6,7,8-\mathrm{HCDF}$ & 0.1 & 718 & 3 & 4 & $<2$ \\
\hline $1,2,3,7,8,9-\mathrm{HCDF}$ & 0.1 & 59 & $<2$ & $<2$ & $<2$ \\
\hline $1,2,3,4,6,7,8-\mathrm{HpCDF}$ & 0.01 & 2284 & 6 & 6 & $<3$ \\
\hline 1,2,3,4,7,8,9-HрCDF & 0.01 & 330 & $<3$ & $<3$ & $<3$ \\
\hline $1,2,3,4,6,7,8,9-\mathrm{OCDF}$ & 0.0001 & 1735 & $<5$ & $<5$ & $<5$ \\
\hline TEQ (pgTEQ/ml) & & 364 & 2.0 & 2.2 & $<1.0$ \\
\hline Total I-TEQ (pgTEQ/ml) & & 572 & 27.4 & 9.4 & $<3.3$ \\
\hline
\end{tabular}

a Symbol "<" indicates that the concentration is under the detectability limit; in this case for the purpose of calculating TEQ, the concentration is always assumed $=1 \mathrm{pg} / \mathrm{ml}$.

$25 \mathrm{pg} / \mu \mathrm{l}$ in a $10 \mu \mathrm{l}$ final volume, lower respect to the one recommended by the US-EPA (200 ppt in a $20 \mu \mathrm{l}$ ). This was done in order to allow a more realistic estimate of the actual concentration of native analytes, and therefore a better approximation of their behavior during extraction, concentration, and chromatographic analysis.

When the whole reaction mixture was analyzed, the solid $\mathrm{Pd} / \mathrm{C}$ catalyst was separated from the reaction mixture by filtration, and boiled in toluene for $24 \mathrm{~h}$ to recover residual PCDDs and PCDFs.

The HRGC/HRMS analyses were conducted using a HP 6890 plus gas chromatograph coupled to a Micromass Autospec Ultima mass spectrometer operating in EI mode at $35 \mathrm{eV}$ and with a resolution of 10.000 (5\% valley). Sample injections were performed in the splitless mode on a $60 \mathrm{~m}$ Rtx $5 \mathrm{~ms}$ column $(0.25 \mathrm{~mm}$ i.d., $0.25 \mu \mathrm{m}$ film made by Restek), and verified on a $60 \mathrm{~m}$ Rtx 200 one $(0.25 \mathrm{~mm}$ i.d., $0.25 \mu \mathrm{m}$ film made by Restek).
The quantitative determination of PCDDs/PCDFs was performed by the isotope-dilution method using relative response factors previously obtained from five standard solution injections [30]. The results are reported in Tables 1 and 2.

\section{Results and discussion}

The working conditions for the hydrodechlorination reaction were initially determined by using nontoxic 2,4,8-trichlorodibenzofuran (TCDF) as a model reaction substrate. The complete reaction pathway of this compound and of all its reaction products could be followed quantitatively by GC-MS. The reaction profiles (Fig. 1) show the disappearance of 2,3,7,8-TCDF, then of the trichloro, followed by the di- and monochloro compounds, with observed first-order kinetics [25]. By using $\mathrm{Pd} / \mathrm{C}$ as the catalyst and Aliquat 336 (A336) as the PT agent, complete conversion to dibenzofu- 
ran (DF) was achieved in about $1.5 \mathrm{~h}$, while after the same time, $\mathrm{Pt} / \mathrm{C}$ yielded only minor amounts of fully dechlorinated product. Thereby confirming that $\mathrm{Pd} / \mathrm{C}$ is the catalyst of choice for the hydrodechlorination (as was for PCBs and halobenzenes [18-21]).

Two different mixtures collected from different sites (labeled A and B) of the 17 toxic congeners of PCDDs and PCDFs and of their nontoxic isomers, obtained by the extraction from MSWI fly ash, were set to react with $\mathrm{Pd} / \mathrm{C}$ as the catalyst, under the same reaction conditions as for $2,4,8$-TCDF. These reactions were followed quantitatively by the disappearance of each PCDD/PCDF congener, and not by monitoring the formation of the products like for the model compound. The results, reported in Tables 1 and 2, show the decrease of the PCDD/PCDF concentrations in the organic phase versus the reaction time. A column also reports the accepted values of the toxic equivalency factor. The concentration of all the analytes becomes undetectable by GC-HRMS after $2 \mathrm{~h}$.

The most toxic congener 2,3,7,8-TCDD is the most thermodynamically stable [31], and is presumably formed during the reaction by the successive hydrodechlorination of the more chlorinated congeners. In fact, 2,3,7,8-TCDD in sample B shows a slight initial concentration increase before being dechlorinated. 2,3,7,8-TCDF and 2,3,7,8-TCDD in sample A on the other hand show no such behavior and react rapidly from the very beginning. The other PCDD/PCDF congeners are dechlorinated with comparable rates.

The data can also be interpreted as the decrease of the toxic equivalent TEQ of both samples as a function of time, as shown in Fig. 2, where for both samples A and B, the logarithm of the TEQ decreases very rapidly, indicating that the degradation of the PCDDs/PCDFs is extremely efficient. We can speculate that the observed lower reactivity of sample B is due to the presence of toluene from the extraction procedure, which was absent in sample A. Unlike hexane, toluene solubilizes A336 and removes it from the catalyst surface to a certain extent. This modifies the catalytic environment and slows the hydrodechlorination reaction [18-20].

The sharp concentration decrease in the beginning of the reaction along with the hydrodechlorination rates for the majority of PCDDs/PCDFs suggest that the reaction proceeds preferably by mass-transfer control. The excess of $\mathrm{Pd} / \mathrm{C}$ respect to the PCDDs/PCDFs

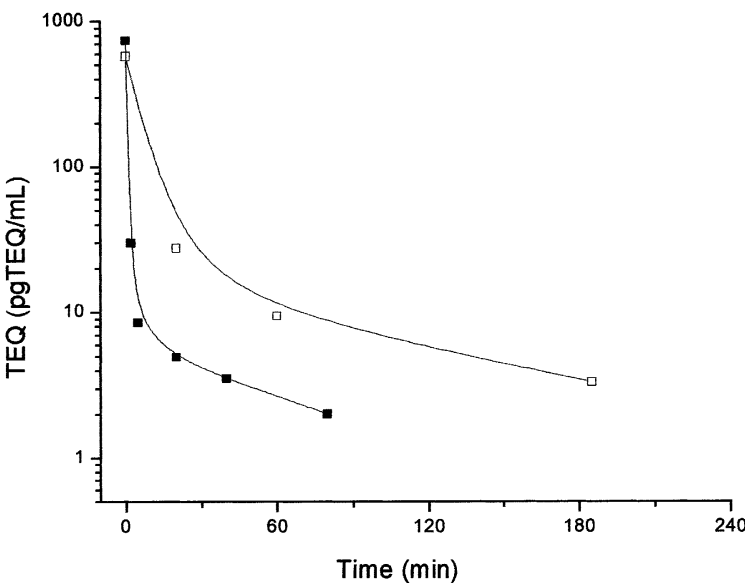

Fig. 2. TEQ decay of PCDD/PCDF samples A ( $\square$ ) and B ( $\square$ ) with time.

probably causes adsorption of the PCDDs/PCDFs over the surface of $\mathrm{Pd} / \mathrm{C}$ in the beginning of the reaction. This may explain the sharp initial decrease in the concentration of PCDDs/PCDFs and the fact that hydrodechlorination rates of each congener appear to be of the same order of magnitude, since the reaction rate is likely controlled by the adsorption-desorption of PCDDs/PCDFs and not by the intrinsic hydrodechlorination rates.

The results do not allow a direct comparison between the reactivity of PCDDs/PCDFs with those of the model substrate $2,4,8-\mathrm{TCDF}$, or PCBs, or polychlorobenzenes under the same conditions, since the present hydrogenation of the PCDD/PCDF samples was run using a large excess of catalyst (approximately $10^{7}$ ) and PT agent with respect to the substrate. Nevertheless, we do not foresee any reason for a pronounced difference between the rates of the hydrodechlorination reactions of the toxic PCDD/PCDF congeners and of 2,4,8-TCDF.

A possible problem, related to the excess of catalyst used, is adsorption of the PCDDs/PCDFs on the carbon support, which may conceivably lead to misinterpretation of the analytical data. The error would occur if the PCDDs/PCDFs were simply adsorbed unchanged by the supported catalyst without being dechlorinated, thereby disappearing from the HRMS spectrum and providing misleading analytical data for the degradation. We feel that we can neglect 
this possibility for a number of reasons. First, in the reaction with the model 2,4,8-TCDF, we observed the reduction products which tell us the reaction is in fact occurring. Secondly, we performed a test experiment where the whole reaction mixture (organic and aqueous phase, and the $\mathrm{Pd} / \mathrm{C}$ catalyst), including the solid portion, was analyzed for PCDDs/PCDFs. The experiment was done by spiking the mixture with a series of $15{ }^{13} \mathrm{C}_{12}$-labeled 2,3,7,8-PCDD/PCDF-substituted isomers as internal standards working through the extraction procedures, and finally analyzing the total dioxin content. The results showed that the labeled PCDD/PCDF isomers were recovered in 20\% yield, but that no unreacted dioxins were present. The conclusion is that an absorption process does exist which causes the fast initial disappearance of PCDDs/PCDFs, but that eventually the dioxins do undergo hydrodehalogenation, as testified by their complete absence in the mixture. Finally, to confirm the hypothesis that it is not simply adsorption responsible for the disappearance of the PCDDs/PCDFs, a duplicate experiment was run on sample A, but without hydrogen. In this case, an initial decrease of the total TEQ was observed, which however did not disappear but remained approximately constant and well over the minimum detection level, thereby confirming that the complete disappearance of the contaminants is due exclusively to their undergoing the hydrodechlorination reaction and not simply to adsorption on the activated carbon catalyst support.

\section{Conclusions}

New multiphase hydrodechlorination conditions were successfully used for the degradation of polychlorinated dibenzo-dioxins and -furans. The results show that complete hydrodechlorination of all 17 toxic PCDD/PCDF congeners occurs rapidly and under very mild reaction conditions. The sharp concentration decrease in the beginning of the reaction suggests that the reaction is probably controlled by mass transfer as well as adsorption processes. Since the two samples which were used were prepared in different solvents, and since the HDX reaction proved successful on both, the applicability of the described HDX reaction seems relatively general.
Future studies will be aimed at the optimization of the conditions, and at understanding the mechanism and the kinetics of the reaction in order to develop this method into a practical tool to be used for the on-site detoxification of small concentrated incinerator samples containing PCDDs and PCDFs.

\section{Acknowledgements}

This work was supported by INCA (Interuniversity Consortium Chemistry for the Environment). We gratefully acknowledge Dr. Stefano Raccanelli for the analyses, and we thank Prof. Sergei S. Yufit for his help in preparing this work.

\section{References}

[1] P. Tundo, S. Facchetti, W. Tumiatti, U.G. Fortunati, Chemosphere 14 (1985) 403.

[2] R.B. LaPierre, L. Guczi, W.L. Kranich, A.H. Weiss, J. Catal. 52 (1978) 230.

[3] G. Tavoularis, M.A. Keane, J. Mol. Catal. A: Chem. 142 (1999) 187.

[4] P. Forni, L. Prati, M. Rossi, Appl. Catal. B: Environ. 14 (1997) 49.

[5] F. Murena, E. Schioppa, Appl. Catal. B: Environ. 27 (2000) 257.

[6] B. Coq, G. Ferrat, F. Figueras, J. Catal. 101 (1986) 434.

[7] C. Schüth, M. Reinhard, Appl. Catal. B: Environ. 18 (1998) 215, and references therein.

[8] Y. Cesteros, P. Salagre, F. Medina, J.E. Sueiras, Appl. Catal. B: Environ. 25 (2000) 213.

[9] Y. Ukisu, S. Rimura, R. Uchida, Chemosphere 33 (1996) 1523.

[10] Y. Ukisu, T. Miyadera, J. Mol. Catal. A: Chem. 125 (1997) 135.

[11] Y. Ukisu, S. Kameoka, T. Miyadera, Appl. Catal. B: Environ. 18 (1998) 273.

[12] Y. Ukisu, S. Kameoka, T. Miyadera, Appl. Catal. B: Environ. 27 (2000) 97.

[13] L. Renberg, N.G. Johansson, C. Blom, Chemosphere 30 (1995) 1805.

[14] R. Weber, T. Sakurai, H. Hagenmaier, Appl. Catal. B: Environ. 20 (1999) 249.

[15] R. Hilarides, K.A. Gray, J. Guzzetta, N. Cortellucci, C. Sommer, Environ. Sci. Technol. 28 (1994) 2249.

[16] S. Vollmuth, R. Niessner, Chemosphere 30 (1995) 2317.

[17] Z. Qin, Chemosphere 33 (1996) 91.

[18] C.A. Marques, M. Selva, P. Tundo, J. Chem. Soc., Perkin Trans. 1 (1993) 529.

[19] C.A. Marques, M. Selva, P. Tundo, J. Org. Chem. 58 (1993) 5256. 
[20] C.A. Marques, O. Rogozhnikova, M. Selva, P. Tundo, J. Mol. Catal. A: Chem. 96 (1995) 301.

[21] C.A. Marques, M. Selva, P. Tundo, J. Org. Chem. 59 (1994) 3830.

[22] C.A. Marques, M. Selva, P. Tundo, J. Org. Chem. 60 (1995) 2430.

[23] M. Selva, P. Tundo, A. Perosa, J. Org. Chem. 63 (1998) 3266.

[24] A. Perosa, M. Selva, P. Tundo, J. Org. Chem. 64 (1999) 3934.

[25] P. Tundo, S. Zinovev, A. Perosa, J. Catal. 196 (2000) 330.

[26] P. Tundo, C.A. Marques, M. Selva, Rend. Fis. Acc. Lincei 3 (1992) 284
[27] M.A. Aramendia, V. Borau, C. Jiménez, J.M. Marinas, M.E. Sempere, P. Urbano, Appl. Catal. 43 (1988) 41.

[28] M.A. Aramendia, V. Borau, J.F. Gómez, A. Herrera, C. Jiménez, J.M. Marinas, J. Catal. 140 (1993) 335

[29] Assessment of the health risk of dioxins: re-evaluation of the tolerable daily intake (TDI), Executive Summary of the World Health Organization Consultation, Geneva, Switzerland, 25-29 May 1998, http://www.who.int/pcs/pubs/dioxin-execsum/exe-sum-final.html.

[30] US-EPA Method 1613: Tetra- through Octa-Chlorinated Dioxins and Furans by Isotope Dilution HRGC/HRMS.

[31] S.S. Yufit, Mendeleev Commun. 4 (1999) 144. 